\title{
A CIDADE ENTRE IMAGENS E IMAGINÁRIOS: ALGUMAS CONTRIBUIÇÕES DOS OLHARES SKATISTAS
}

\author{
Luiz Antonio Feliciano ${ }^{1}$
}

\section{Introdução}

A fotografia tem seu lugar assegurado no seio das relações humanas. Com toda sua potencialidade imagética, ela se configura num suporte privilegiado para interfacear o vivido no passado, a lembrança no presente e as rememorações no futuro. Contudo, ela traz apenas vestígios do vivido. São formas expressivas de um conteúdo apresentado. Todo acumulado de impressões dos fenômenos presenciados e apreendidos são à base das expressões. Se por um lado, o conteúdo é como as coisas se apresentam ao sujeito, por outro, a expressão é como o sujeito apresenta, ao Outro, a maneira como as coisas se apresentaram a ele (Deleuze, 1995). Um processo de desterritorialização tanto de conteúdo (impressões apreendidas do fenômeno) quanto de expressão (forma de apresentar as impressões apreendidas). Não há uma simultaneidade entre os dois fenômenos. No entanto, eles estão imbricados em um mesmo agenciamento. Contudo, em um processo de desterritorialização, conteúdo e expressão se afetam mutuamente em uma simbiose necessária e constante. A imagem fotográfica traz uma expressão visual de um conteúdo observado e fotografado. Uma maneira de tentar reatualizar aquilo que foi vivenciado. Na atualidade, essas expressões visuais pululam o cotidiano das pessoas, principalmente pela utilização maciça das redes sociais online.

$\mathrm{O}$ advento da tecnologia informacional possibilitou novas maneiras para o jovem vivenciar os espaços urbanos (Martín-Barbero, 1997). O universo online contribui para uma aproximação entre os grupos. Além da interação, a internet engendrou outros modos de se afirmar enquanto grupo na sociedade (Márquez; García, 2015). Os aparelhos híbridos disponibilizados no mercado facilitaram a produção e a distribuição de mensagem, sobretudo aquelas calcadas nas visualidades. A produção de imagens e a veiculação real time ilustram, de certa maneira, as permanências ou as ausências em determinado lugar e os modos como os lugares ressignificados. Comunicabilidade e

\footnotetext{
${ }^{1}$ Universidade do Estado de Minas Gerais, Brasil. Email: liufeliciano@gmail.com ORCID id: https://orcid.org/0000-0001-9316-6883
} 
visibilidade que se incorporam às vivências diárias de quem produz e de quem recebe a mensagem. Contudo, a imagem quando veiculada, curtida e/ou compartilhada, ganha outras ressignificações. E necessariamente, os espaços urbanos representados nas imagens ganham mais realidade do que o próprio local onde o fato aconteceu. Essa vivência tecnologizada e virtualizada tem contribuído para novas configurações de sujeitos, de socialidades, de experiências urbanas e de imaginários sociais sobre a cidade. As imagens da cidade, sejam elas técnicas ou literárias, acabam por construir uma cidade que sobrevive no imaginário das pessoas (Calvino, 1993; Solà-Morales, 1995; Tomaz, 2002).

Nesse trabalho, procura-se discutir o papel da imagem na construção da cidade presente no imaginário coletivo e a funcionalidade dos aparatos tecnológicos nas construções subjetivas e no fortalecimento de uma cultura urbana. As discussões partem de observações a um grupo de skatistas, em uma pista de skate, numa cidade do interior de São Paulo. Ficou evidente a importância que os jovens davam ao celular que carregavam. Era o skate em uma mão e o aparelho na outra. Umas vezes, era utilizado para fotografar ou gravar um vídeo. Outras vezes, era uma mensagem para um amigo ou o acesso a um site de relacionamento. Alguma vezes, recebiam ou faziam uma chamada. E quando estavam deslizando sobre o skate, o celular tocava a música preferida, com os fones colados aos ouvidos. É impossível pensar o jovem skatista separado do seu celular. Essa intensidade na utilização do aparelho tem reflexos nas suas relações com o outro, com o grupo, com o espaço. Desse modo, o texto procura trazer algumas problematizações que nascem desses novos modos interativos de relacionar-se, sobretudo, entre os skatistas. Problematiza-se, ainda, os respingos dessas atitudes nas imagens produzidas sobre a cidade e as contribuições para a construção do imaginário

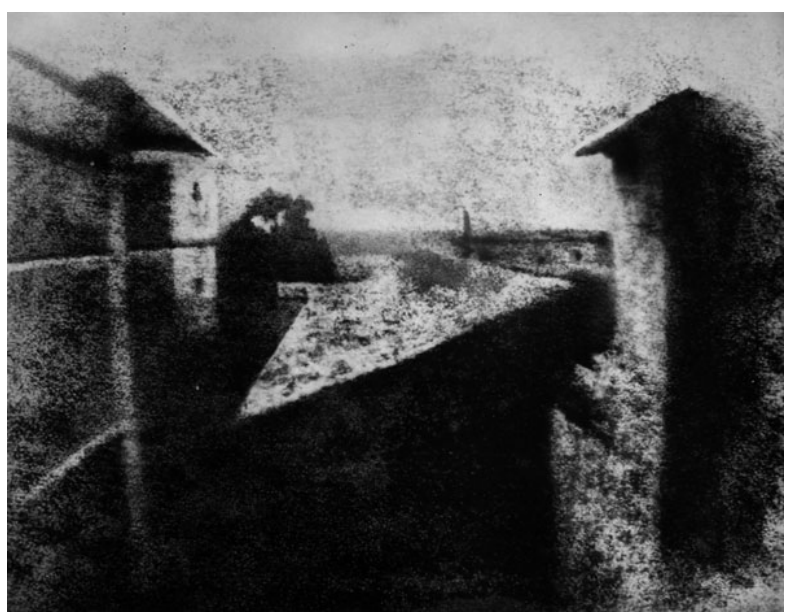

IMAGEM 1 - Point de vue du Gras, 1826 - Joseph Nièpce. sobre a cidade. Espera, contudo, contribuir para um olhar mais atento sobre os jovens como produtores de conteúdos e colaboradores na construção de uma percepção mais humana dos espaços vivenciados, no interior das cidades. 


\section{Imagem fotográfica, imagem da cidade: contribuições para uma etnografia visual}

A fotografia tem uma forte relação com a cidade. Para ser mais justo, ela nasce praticamente junto com a expansão das cidades (Sánchez Montalbán, 2002; SolàMorales, 1995). Desde aquele "Point de vue du Gras",2 de Joseph Níèpce, e a famosa "Boulevard du temple", , de Louis Daguèrre, a cidade passa a ter a fotografia como sua companheira inseparável na fixação da sua imagem e de seus imaginários. Muito do que se sabe das cidades do passado, e mesmo de cidades contemporâneas, é construído pelo que a fotografia apresenta (Sánchez Montalbán, 2002). Uma preservação carregada dos interesses de quem, naquele determinado momento, produziu a imagem (Roa, 2002). A valorização da imagem fotográfica se dá pela necessidade que o indivíduo tem de um passado (Roa, 2002). O que se procuram nas fotografias da cidade são os signos que permitem reavivá-la. Nesse caso, a memória é utilizada como o lugar da montagem e, por conseguinte, o imaginário tem a função de preencher os vazios para que a imagem se revista conotativamente de vestígios (Thomaz, 2002; Roa, 2002).

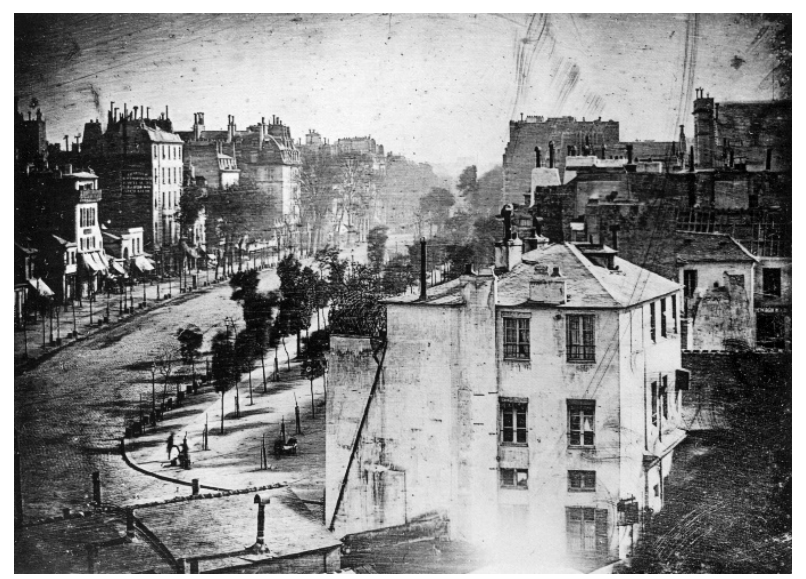

IMAGEM 2 - Boulevard du temple, 1838 - Louis Daguerre

Nesse sentido, o que emana da imagem prende a cidade à fotografia. A percepção tem uma função primordial nesse processo ao organizar as formas que criam o sentido imanente, que amarram a cidade às suas imagens. $\mathrm{O}$ desenho oferecido pelas imagens fotográficas atualiza os desígnios da cidade como existência e como memória. Como processo dialético, a recriação e interpretação de sentidos para a cidade requer um duplo movimento: por um lado, incluem-se elementos que a transformam em informação e conhecimento e, por outro, excluem uma não-cidade ou, melhor, uma cidade-ausência (Thomaz, 2002). A maneira que o tempo se esvai, as cidades da memória tornam-se invisíveis e se desvanecem nas lacunas do esquecimento (Calvino, 1993). Restam, tão somente, os vestígios de sentidos de passado reelaborados nas imanências da fotografia que o

\footnotetext{
2 Título da primeira fotografia de Joseph Nicéphore Nièpce, na cidade de Saint-Loup-de-Varennes, França, em 1826-27.

${ }^{3}$ Realizada por Louis Daguerre, em 1938, na cidade de Paris, essa é a primeira fotografia que mostra um ser humano.
} 
imaginário reconstrói na distância temporal entre a imagem e o momento do clique (Thomaz, 2002). O olhar constrói uma imagem da cidade que quando registrada, em fotografias ou outros suportes, como o vídeo, se incorpora à memória coletiva e ao imaginário social (Solà-Morales, 1995; Roa, 2002). Isso torna a cidade do passado representada na imagem, mais real do que a cidade vivenciada de fato.

Essa crença cega em seu próprio reflexo serviria como exemplo de como as ideias hegemônicas ganham força de representação e praticamente substituem os testemunhos e as vivências várias da cidade por uma imagem única, como uma força aglutinadora que, ao permitir a criação de uma identificação para diversos grupos, exclui, ao mesmo tempo, a possibilidade de percebermos as experiências singulares, os movimentos e percursos amplos de que suas imagens/vestígios podem ser testemunhas. Esse reflexo luminoso, movediço e transitório se cristaliza e, fossilizado, pouco tem a dizer. (Thomaz, 2002: 442).

A hegemonia da imagem fotográfica substitui os testemunhos e as vivências das várias cidades existentes em um mesmo lugar. Ao admirar a imagem perde-se a possibilidade de olhar as novas experiências. Nesse sentido, a fotografia com seus enviesamentos e seus paradoxos necessita ser potencializada para contribuir com as pesquisas, tanto no campo da antropologia, como em outras do conhecimento.

Para Solà-Morales (1995), a fotografia é um instrumento privilegiado para representação da metrópole. Seu desenvolvimento técnico e estético tem fornecido diferentes sentidos na relação com a arquitetura que praticamente torna-se quase impossível separar os conhecimentos sobre arquitetura moderna dos conhecimentos introduzidos pelos olhares dos fotógrafos sobre a cidade. Não há como separar uma experiência direta e verdadeira, dos edifícios, das ruas e dos espaços urbanos, de outra mediada pela fotografia. Na história da arquitetura do século XX há sempre a referência aos fotógrafos.

La percepción que tenemos de la arquitectura es una percepción estéticamente reelaborada por el ojo y la técnica fotográfica. La imagen de la arquitectura es una imagen mediatizada que, según los recursos de la representación plana de la fotografía nos facilita el acesso y la comprensión del objeto. (Solà-Morales, 1995: s. P).

A fotografia tem construído o olhar e o imaginário sobre a cidade, assim como outros suportes comunicacionais, e, igualmente, tem se constituído primordial na experiência visual da cidade. A potencialidade inicial da fotografia não oferece a cidade, mas, sim, indícios que colaboram na construção de um imaginário estabelecido com o lugar. Solá-Morales (1995) atenta para o fato da imagem fotográfica, além de comunicar as percepções que se tem da cidade, transmitir, também, as afecções subjacentes da 
experiência do/no lugar, que se convertem em juízos de valor sobre o espaço vivenciado. Nesse sentido, a fotografia tende a oferecer problematizações sobre os usos e as inutilidades dos espaços e dos lugares, além da presença ou da ausência do Outro (Tuset, 2012) na cidade e outros modos de estranheza diante da vida contemporânea.

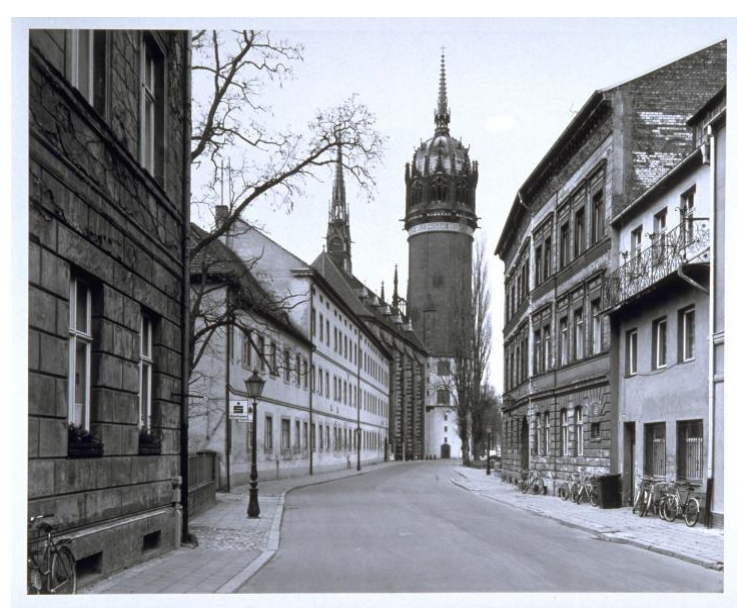

IMAGEM 3 - Schlosstrasse, Wittenberg, 1991 Thomas Struth.
Tuset (2012) traz a discussão em torno da imagem do Outro nas fotografias de arquitetura. Uma das suas abordagens discute a importância do retrato e do jogo relacional que este encerra. $\mathrm{O}$ rosto em si, é um signo de humanidade, que para o fotógrafo é fascinação e mistério e para o observador é questionamento sobre quem é o retratado e qual a intenção do fotógrafo. O papel de toda fotografia é causar um estranhamento que conduza a

uma interação de quem observa a imagem com o Outro, da imagem ou o produtor dela, ou, ainda, consigo mesmo. As fotografias de arquitetura tem esse mesmo legado de suscitar estranheza e conduzir questionamentos acerca da relação do indivíduio com o seu espaço. No entanto, a contemporaneidade tem enxotado a sociedade a um labirinto de imagens que transforma a percepção da realidade e obriga a um constante zapeamento para suprimir aquilo que não interessa. Esse constante selecionamento de imagens tem condicionado a produção de significados de maneira inconsciente. Ao abordar fotógrafos como Julius Shulman e Thomas Struth, Tusset (2012) faz uma leitura do sentido que a ausência das pessoas causa nas imagens. São edifícios, em ruas vazias, onde opera a ausência de movimentos, de ruídos e de pessoas. Silenciosas, elas ferem o espectador que não reconhece nelas experiências urbanas tradicionais. Indiferentes ao cotidiano, são cidades idílicas, utópicas e melancólicas, em seus rostos representacionais. "Os dois fotógrafos reclamam ao expectador e provocam nele outro modo de recepção da imagem cultural da cidade (Tuset, 2012: 96)”.

A fotografia com esses dilemas tem ajudado, juntamente com a literatura e o cinema - e mais recentemente o vídeo -, a formatar as cidades e urbanidades que hoje se conhece. Ela tem se configurado, com o seu percurso, em uma ferramenta 
importante, mesmo com suas limitações e seus paradoxos, para entender o contexto humano. Quando associada à cidade, ela consegue retratar diversas facetas da cotidianidade, além de contribuir para o conhecimento de outros lugares. Porém, a fotografia está intimamente ligada aos interesses tanto do fotógrafo como também, do leitor (Sánchez Montalbán, 2002; Escallier, 2009). Por esse viés, ressalta-se a retórica da cidade transladada com o ato fotográfico. Suas expressões diversas, seus espaços conotados e sua fragmentação podem produzir discursos diversos, ainda mais convincentes, quando ligados à fotografia.

La fotografia, de una ciudad, es algo más que la representación de un espacio o una actividad, sino que se configura como una pantalla aberta a la interpretación y a las sensaciones vitales y emocionales de lo representado. (Sánches Montalbán, 2002: 78).

As fotografias têm seus valores próprios e sua valoração independe de sua qualidade material. Muitas vezes, algumas imagens configuram a única verdade sobre o lugar, sobretudo, quando não existem outras imagens para serem comparadas. Nesse sentido, as construções mentais, baseadas na experiência e na percepção da cidade, ganham reforço com as imagens realizadas dessa cidade. A polifonia e a polissemia da imagem fotográfica, capturadas de maneiras diversas, tende a produzir uma cidade no imaginário coletivo. Qualquer fotografia produzida, seja ela profissional ou amadora, contribui para a construção da imagem da cidade (Roa, 2002). Como a imagem tem um poder evocativo, tanto para o estudioso quanto para o cidadão comum, a leitura dessa produção visual pode ganhar conotações diferenciadas (Escallier, 2009). Se para o olhar comum, as fotografias servem como auxílio à memória, isto é, apenas evocações de recordações, para o pesquisador, ela oferece uma riqueza de informações que pode subsidiar problematizações consistentes sobre os habitantes e suas relações com a cidade. Essas abordagens dos usos da fotografia na história, na antropologia, na arquitetura ou no cotidiano, apontam de maneira superficial a potencialidade e os paradoxos da fotografias. Por um lado, atenta para os discursos que sua linguagem refratária consegue construir e, de outro, aponta para a homogeneização dos sentidos operados pela ilusão reflexiva do duplo da realidade. Contudo, a possibilidade de transitar por esses dois campos lhe confere a dinamicidade necessária para permear, em certo sentido, as relações sociais e as possíveis pesquisas no campo da ciências sociais e humanas quando, estas, são auxiliadas pelo suporte imagético. 


\section{Experiências sensíveis ou os olhares skatistas sobre a cidade}

Os avanços tecnológicos na produção e veiculação de imagens potencializaram exponencialmente a visibilidade dos grupos urbanos e o skate mão ficou fora desse movimento. Uma transformação sentida por todo o universo da comunicação e da sociedade. Tem-se, na contemporaneidade, uma nova estética visual, sobretudo, no cinema e no audiovisual (Parente, 2007). A pulverização da câmera hibrida ${ }^{4}$, incorporada pela $\mathrm{DSLR}^{5}$, produtora de imagens, permitiu essas mudanças. O barateamento do equipamento facilitou o acesso e colocou as câmeras nas mãos de quase todas as pessoas (Bruno, 2013). São várias histórias, contadas de diversas maneiras, veiculadas em diferentes sites e acessadas por múltiplas pessoas. Além das câmeras DSLR, os celulares, também híbridos, dispõem de uma variedade de recursos que facilitam a captura de imagens tanto em fotografia, como em vídeo. Esses aparelhos estão nas mãos dos skatistas, e outros fenômenos culturais, dando a possibilidade de produzirem suas próprias mensagens. Entre os skatistas, a preferência é pelo vídeo.

A gente gosta mais de vídeo pra poder mostrar que foi perfeito, que a gente acertou mesmo, porque na foto muitas vezes a gente pode fazer assim, a gente acertou a foto, acertou a manobra, mas a foto que a gente colocou foi uma que a gente não acertou, mas ficou mais bonito, é isso. (LEO - skatista em São José dos Campos-SP. 13/12/2016).

Uma escolha que se justifica pela relação da imagem em movimento com o desenvolvimento da manobra. A fotografia fica em segundo plano, pois não consegue mostrar a sequência do movimento. Porém, sua importância concentra-se, principalmente, na possibilidade de veiculação em revistas especializadas e para

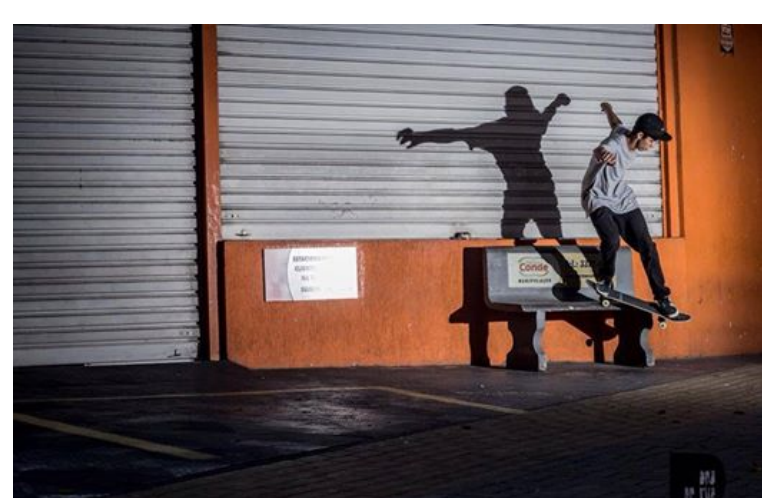
divulgação.

No skate, a gente visa bastante isso porque pra sair numa capa de revista usa a fotografia e é muito importante isso. Os dois, na verdade, são muito importantes não tem como diferenciar. (GIOVANI - skatista em São José dos CamposSP. 23/01/2016).

IMAGEM 4 - skatista Giovani se apropriando da cidade arquivo do próprio skatista

${ }^{4}$ Os aparelhos híbridos concentram, em um só dispositivo, várias funções como: fotografar, gravar, vídeo, gravar áudio. No caso dos celulares, acrescenta-se, ainda, telefone, envio de mensagens de textos, acesso à internet.

${ }^{5}$ Digital Single Lens Reflex são câmeras que trabalham com lente única, para o registro e para a focagem, e com visor penta-prismático. Um jogo de espelho que faz a inversão da imagem, para ser vista de modo normal. 
Machado (2011) traz uma experiência, que presenciou com os sujeitos de sua pesquisa, de uma sessão de fotos em frente ao Banco Central, em São Paulo, para uma revista. Mesmo depois de várias quedas, o skatista não desistiu, pois "naquele momento importante, era utilizar o obstáculo e acertar a manobra, para ter sua foto estampada na capa de uma revista especializada" (Machado, 2011: 157). Barthes (1984) vê um campo de força na fotografia - mas que pode ser estendido para as outras produções visuais em que quatro imaginários intencionalizados atuam, entrecruzando, afrontando e deformando-os mutuamente. "Diante da objetiva, sou ao mesmo tempo: aquele que eu me julgo, aquele que eu gostaria que me julgassem, aquele que o fotógrafo me julga e aquele de que ele se serve para exibir sua arte" (Barthes, 1984: 27). Ninguém sai ileso de uma fotografia ou de um vídeo produzido e veiculado. É muito comum o olhar do skatista para a descoberta de novos picos na cidade, com a intenção de mandar as manobras, principalmente, para a gravação em vídeo.

\begin{abstract}
Vamos lá, vamos procurar os lugares da cidade que tem para andar e isso é legal pega muito bem. Filmar outras cidades sempre estar procurando lugares novos para andar. (GIOVANI - skatista em São José dos Campos-SP. 23/01/2016)

Na verdade, o mais legal é fazer os dois, assim, né. Sempre que dá, porque tipo não é todo mundo que tem o equipamento, né. As câmeras profissionais, tal. Mas a gente sempre tá na rua, tentando filmar, tirar foto... Sempre registrar alguns momentos aí. (MARCELO - skatista em São José dos Campos-SP. 20/02/2016)

A gente gosta mais de vídeo pra poder mostrar que foi perfeito, que a gente acertou mesmo, porque na foto muitas vezes a gente pode fazer assim, a gente acertou a foto, acertou a manobra, mas a foto que a gente colocou foi uma que a gente não acertou, mas ficou mais bonito, é isso. (LEO - skatista em São José dos Campos-SP. 13/12/2016).
\end{abstract}

A intencionalidade da imagem é sempre pautada pela visibilidade que ela proporciona. O modo como o skatista percebe a cidade vem precedido pela vontade de mostrar-se. Bem ao estilo hedonista, parece haver uma relação direta entre o prazer de executar a manobra e a satisfação em ter um público expectador. A facilidade dos aparatos tecnológicos tornou possível o registro imagético da manobra, para ser vista e apreciada por outros, que não estavam presentes. E os jovens contam, assim, suas histórias, imageticamente. Win Wenders (2001) diz, no documentário "Janelas da Alma", que as histórias criam laços afetivos e, hoje, há uma carência de boas histórias. $\mathrm{Na}$ socialidade do grupo, com base na proximidade do território, sobretudo, simbólico, que se constrói pelo afetar-se mutuamente (Maffesoli, 1998), as histórias sobre as andanças pelos picos reforçam os laços grupais. Bachelard (1993: 84), ao comentar as 
análises feitas pela psicóloga Françoise Minkowska sobre desenhos de casas, feito por crianças, diz que "toda grande imagem simples revela um estado de alma". Nesse sentido, o ato de produzir as fotografias ou os vídeos encontra guarida na incorporação de ator e personagem na própria história: uma narrativa que tem um público, de certa maneira, segmentado por um território simbólico, que vai assistir/ouvir a história em um espaço virtualizado.

Como Barthes (1984) referencia a fotografia, pode-se, semelhantemente, identificar diversos objetivos tensionados nesse ato de gravar o vídeo e publicá-lo. Há a intencionalidade do skatista em mostrar sua capacidade técnica, sua perspicácia, sua ousadia, sua criatividade para desenvolver as manobras. Intenção precedida pelo

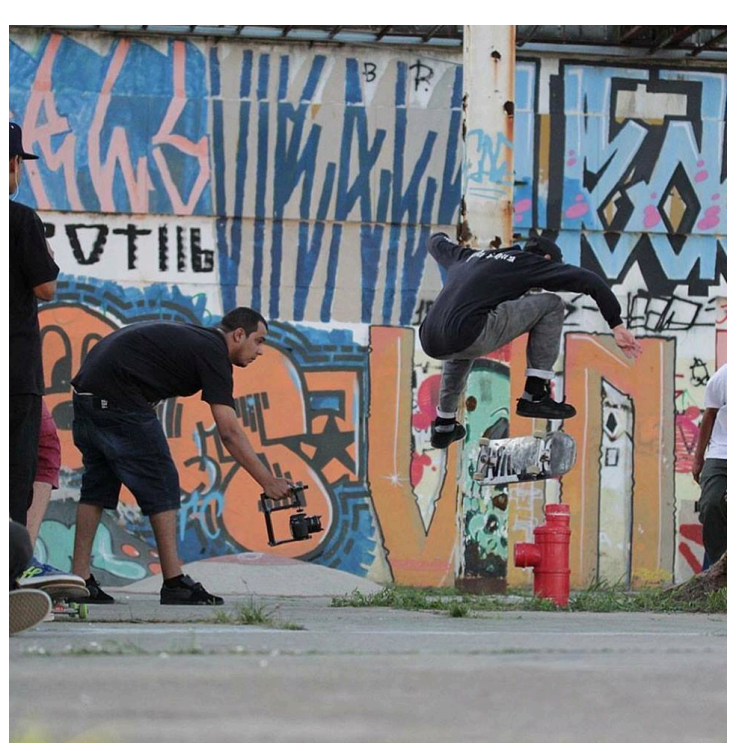

IMAGEM 5 - skatista Marcelo em uma sessão para gravação de imagem - arquivo do próprio skatista. objetivo de exprimir o que ele quer que as pessoas vejam, pois são mostrados somente os acertos. As tentativas frustradas fulguram, na maioria das vezes, na penumbra de um canto qualquer da memória. A possibilidade do corte, da montagem, da edição que suprime o indesejado e que dá um tom estético à obra - trabalho muitas vezes compartilhado entre ator e produtor - é uma dessas maneiras de se eliminar aquilo que não quer que seja visto. Os objetivos de quem produz a imagem embutem-se nessa empreitada. O que ele julga e como ele vê o skatista vai ter grande influência no modo como captura as imagens. Sua criatividade e seu savoir-faire devem aparecer, para o seu reconhecimento junto aos pares e ao público em geral. Acrescentam-se, também, os objetivos de um público potencial que tem acesso ao vídeo, mas não faz parte do skate. Saber que outras pessoas diferentes podem ver as imagens influência à feitura de toda produção. 
Ir a uma pista de skate dá a oportunidade de observar como celular e criatividade, quando se associam, criam boas ideias. É fácil constatar, em cada sessão, a

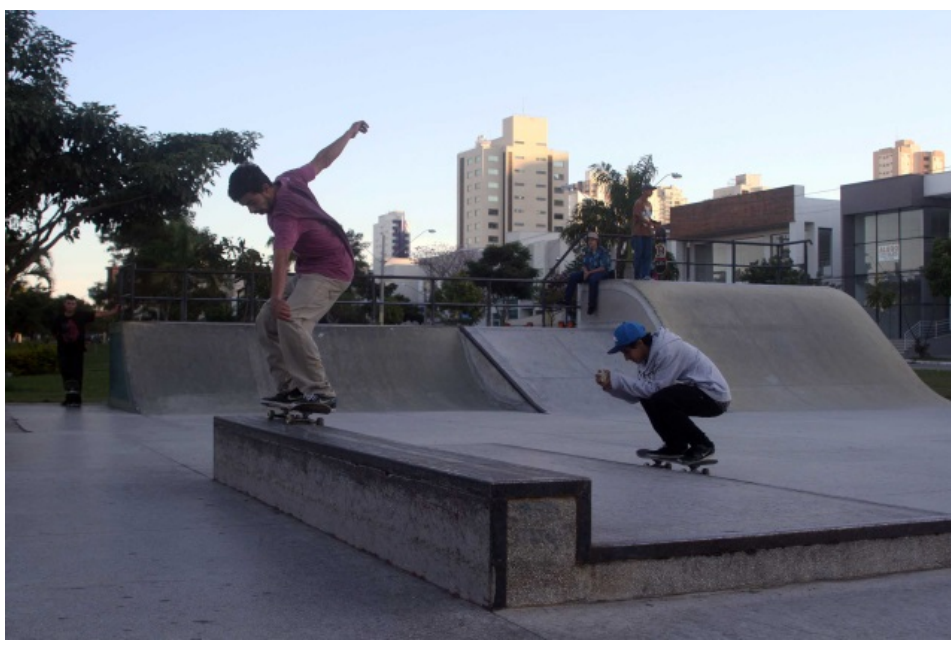

IMAGEM 6 - Manobras e registros na Pista do Aquarius - 27/06/2015 Foto: Liu Feliciano

utilização dos celulares para produzir algumas fotos ou umas gravações. Parecem mesmo duas sessões singulares e complementares ao mesmo tempo. Uma das manobras, outra das imagens. A sessão das manobras é carregada das técnicas que os skatistas dominam muito bem. Por outro lado, a sessão das imagens se enxerta de técnicas que fazem parte da produção do cinema e do audiovisual. Travelling, dolling, pan (panorâmica), plongée são muito comuns no momento da gravação. A maneira como os skatistas desenvolvem as técnicas com o que

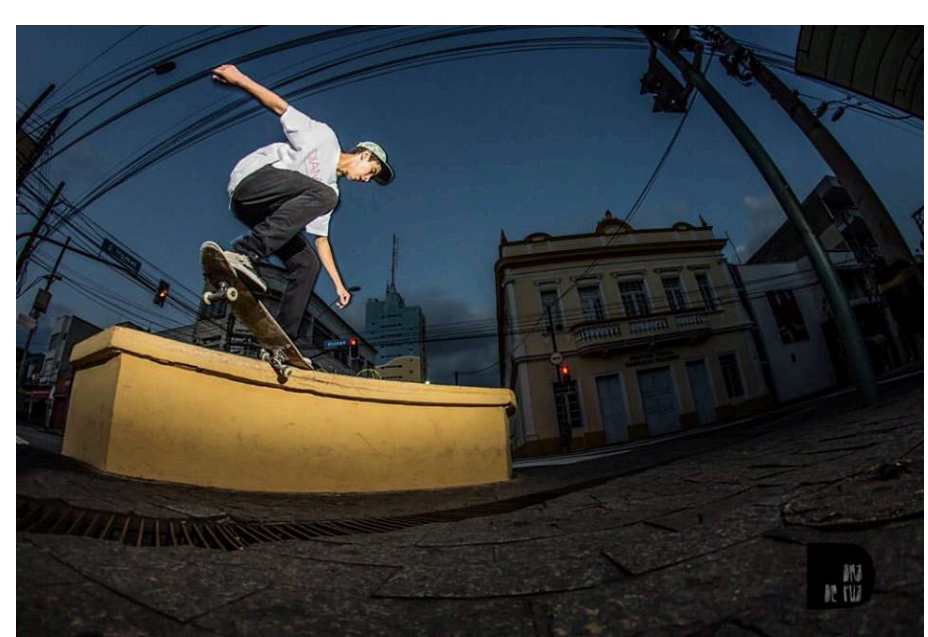

IMAGEM 7 - O skatista Giovani mandando manobra em um mobiliário urbano. Fotografia feita com objetiva grande-angular - arquivo próprio, postada em seu Facebook. têm nas mãos é que é mais interessante. Um exemplo é como fazem o movimento de travilling que "consiste em movimentar o corpo da câmera seguindo o objetivo do quadro" (Oliveira, Cardoso, Beraldo, 2013). Para fazer esse acompanhamento da câmera, paralelo ao personagem, o skatista/câmera sobe no seu skate, começa a deslizar e, em seguida, o skatista/personagem saí com seu skate. Eles seguem a linha até o final. Enquanto um manda nas manobras, o outro manda nas gravações. É uma atividade constante que une companheirismo, solidariedade, técnica, criatividade e afeto.

Outra técnica muito frequente é o tipo de objetiva utilizada na captura da imagem. Tanto nas fotografias, como nos vídeos, a objetiva grande-angular é a mais 
preferida. Essa objetiva é caracterizada pela precisão da superfície, o destaque do primeiro plano e a deformação das formas. Ela também aumenta a distância entre os planos e ressalta as linhas do primeiro plano, acentuando, assim, a ação realizada (Lima, 1988). O "uso das lentes de curta distância focal pôs à disposição da fotografia (e da arte $e$ do vídeo) um novo instrumento de composição fotográfico" (Lima, 1988: 83. Grifo nosso). Ao contrário da objetiva $50 \mathrm{~mm}$, que dá uma visão análoga (representativa) à normalidade do olho humano, a objetiva angular (bizarra) oferece "deformações esquizofrênicas, miragens da realidade, visões alucinatórias" (Machado, 1984: 43). A fotografia é um signo ideológico, pois, mais do que reflexo, ela refrata a realidade fotografada. Por esse viés, essa objetiva reforça, ainda mais, a refração ideológica da cena registrada (Machado, 1984).

Se por um lado, as objetivas de distância focal curta provocam deformações no assunto, por outro, elas comprovam, ao senso comum, que a fotografia (e as imagens técnicas) não é uma verdade absoluta. Dentre os três tipos de objetivas, a teleobjetiva, a normal e a angular, essa última é a que exige mais aproximação do assunto, mais proximidade com a realidade (Machado, 1984). Há uma intimidade maior com o que vai ser registrado, diferente da bisbilhotagem e do olhar clandestino da teleobjetiva. Nesse sentido, a escolha da objetiva angular pelos skatistas parece centrar nessa aproximação que se tem com a realidade fotografada. Olhar uma imagem com esse formato é entrar na realidade que foi capturada no momento da captura.

A imagem - estática e cinésica - tem, ainda, outra função na relação com o skate. Ela serve, para o grupo, como demarcador de um lugar skatável. Os skatistas comentam sobre a dinâmica para identificar um pico na cidade. Nos seus trajetos pelas ruas da cidade, seja de skate, de bicicleta ou de ônibus, ao perceberem um lugar diferente e interessante para mandar as manobras, eles costumam fotografar e compartilhar com os amigos. Assim, todos conseguem visualizar a imagem do local e ter uma ideia se é realmente skatável ou não. A partir do consenso, marca-se a sessão.

As escolhas desses picos podem estar relacionadas apenas à possibilidade de se apropriar de um espaço para mandar as manobras, sem outras intencionalidades. Às vezes, os picos encontrados podem ser bons lugares para uma produção de imagens mais elaborada. Nesse caso, são necessárias negociações para que a sessão aconteça. Segundo Machado (2011: 166), deve se argumentar com os responsáveis que a sessão 
não é para diversão, algazarra, destruição dos mobiliários, mas, sim, para um trabalho profissional. As câmeras e os equipamentos são bons argumentos, nessas horas, pois podem abrir algumas portas, ou melhor, liberar alguns picos (Machado, 2011). Muitas sessões são registradas com muita técnica e profissionalismo, sendo que diversos

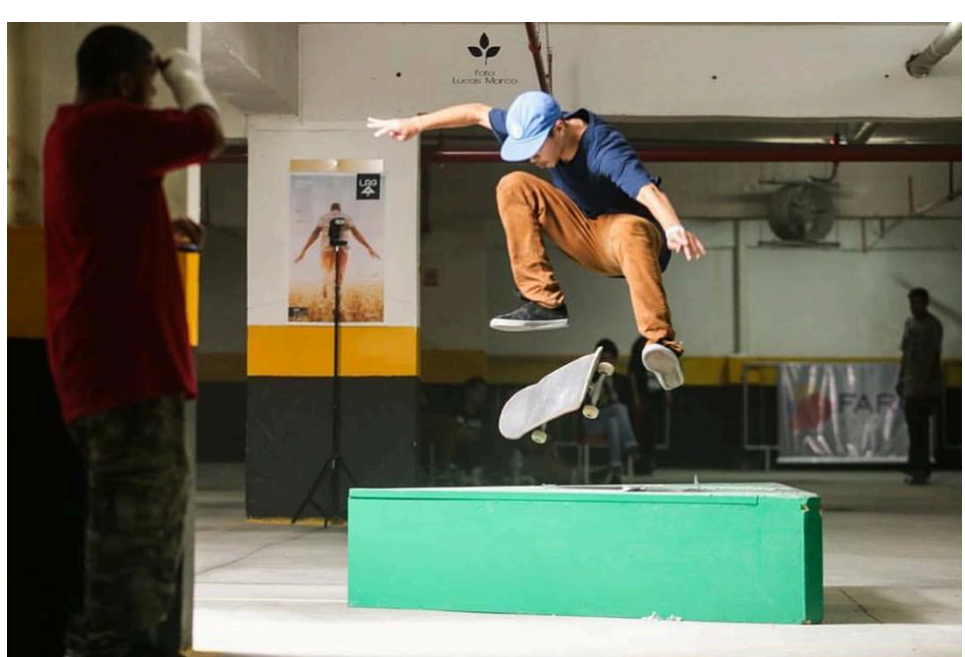
IMAGEM 8 - o skatista marcela em uma sessão para gravação de imagens. skate. Fotografia de arquivo do próprio skatista, publicada em seu facebook.

skatistas

tornaram-se videomakers, especializados em produzir vídeos de skate. Saraví (2012) aborda também, a partir de sua pesquisa em La Plata (Argentina), skatistas que se tornaram videomakers especializados em vídeos de

Às imagens

produzidas, acrescenta-se um caráter didático, pois é comum os skatistas reverem os vídeos produzidos por eles, assim, como, também, os outros vídeos disponibilizados na internet (Saraví, 2012). Geralmente, os skatistas deixam arquivos salvos em seus celulares, para serem vistos em momentos livres, que não se dê para praticar o skate. A fala de um skatista (colocar o nome do skatista) corrobora essa ideia: "Eu tento me concentrar só lá, mas quando eu acabo os estudos eu começo a ver vídeo e tal". Contudo, as imagens estão sempre ligadas ao skate. No registro da manobra, na relação com o Outro, na divulgação da sua prática.

\begin{abstract}
Na dinâmica da praça, os skatistas sempre aplaudem ou comemoram quando alguém acerta uma manobra. Continuo notando isso. Por volta das 16 horas e 10 minutos chegaram mais três meninas skatistas. Esse é o dia com mais meninas aqui na praça. Uma delas chegou, mandou mensagem para uma amiga - escutei o comentário dela com os pais - e logo saíram. Acho que foram para outro pico $^{6}$. Um dos meninos disse para o amigo filmá-lo. $\mathrm{O}$ amigo disse que não iria fazer isso por que a bateria do celular estava acabando e ele não podia ficar sem bateria. (Relato do diário de campo - 03 out. 2015.).
\end{abstract}

Mandar umas manobras, numa pista ou num pico qualquer, necessita estar conectado com o restante do mundo. Uma mensagem aqui, outra ali e a outra acolá é a dinâmica de um mundo transconectado, que transcende o cotidiano (Saraví, 2012). O

\footnotetext{
${ }^{6}$ Pico - Qualquer lugar que tenha alguma coisa que possa ser usado como obstáculo para skate. Disponível em: http://www.tribosjovens.com.br/dicionario-do-skate/
} 
registro da imagem é importante, a solidariedade e a camaradagem também o são, mas ficar sem bateria é coração que não pulsa, é sopro vital que se encerra. Uma socialidade que se dá pela proximidade do estar-junto, carece do lugar de encontro. Como nesses grupos, os territórios podem ser físicos ou simbólicos, a virtualidade ganha status de

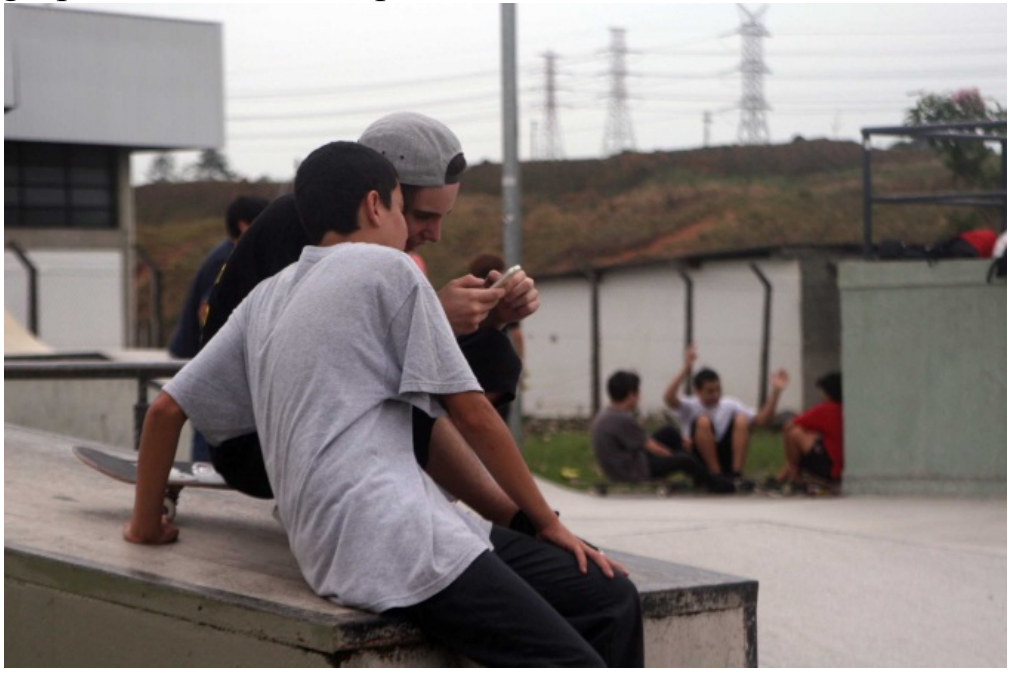

IMAGEM 9 - Pista é lugar de manobras, de imagens e de curtidas. 03/10/2015 - Foto: Liu Feliciano lugar. Facebook, whatsapp, instagram, snapchat, entre outros aplicativos que deixam qualquer um conectado, estão aí para tornar os territórios mais próximos. Os grupos se multiplicam e a presença em cada um deles é "quase" obrigatória. $\mathrm{Na}$ mesma

rapidez que se criam, eles se desfazem e os membros se reencontram no próximo grupo que foi reconfigurado. Múltiplos grupos, múltiplas conexões, múltiplos papéis que desembocam, por vezes, em um lugar físico, num tempo comum a todos os membros. A internet se transforma em um espaço de conversação, de acordos, de novas formas sociocomunicativas (Paredes, 2006).

Nesse espaço virtual, os skatistas encontram "espaço". Espaço de visibilidade, de encontro, de conversa, de reconfiguração de grupo. Espaço de interação e de acesso a informações sobre skate, ideal para novos aprendizados (Bastos, 2006: 50). Além de aprender, pode-se ensinar. Cada vídeo postado é uma contribuição para o aprendizado do Outro e para a divulgação e manutenção do skate (Saraví, 2012; Machado, 2011). Toda imagem compartilhada é discurso lançado ao vento (na nuvem), que se torna eco, que ressoa num vale de curtidas e compartilhamentos. Não é somente de skate que fala uma fotografia ou um vídeo, de uma manobra ou de uma sessão, quando são postados. É de skate, é de skatista, é de jovem, é de lugar, é de cidade, é de relação. Cada imagem é um discurso intencional sobre essas coisas todas, “juntas e misturadas” (Sánches Montalbán, 2003; Escallier, 2009). Esses ecos visuais contribuem na formação do imaginário social de cada uma dessas coisas. A ideologia que o dispositivo imagético carrega compõe um discurso associado à ideologia do enunciador. Ninguém sai ileso de 
uma imagem, principalmente, aquele que a observa. A imagem do que foi fotografado fica registrado na memória e, com o tempo, torna-se o único resíduo do referente. A imagem da cidade acaba transformando-se na cidade que sobrevive nas gretas de uma memória social (Solà-Morales, 1995; Roa, 2002). E com toda essa grande teia, vale ressaltar que a internet é meio e não fim. O fim é pra onde o meio conduz.

As redes sociais online estão aí, assim como, as off-line também continuam na ativa. Todas para serem usadas e para fortalecer o ombro-a-ombro, o estar-junto-a-toa. Pelas conversas com os skatistas e pelas observações realizadas na pista deu pra perceber o quanto eles utilizam das potencialidades e possibilidades da tecnologia digital, online e off-line. Para marcar uma sessão, para descobrir novos picos, para ver vídeos de skate, para produzir e "subir" as suas imagens. São diversas as formas de se utilizar desses recursos e eles têm feito isso bem. Os jovens pensam o mundo como videoclipes, assinala Reguillo (2000: s. P). Um formato de sucessões de imagens, raramente harmônicas, que sintetiza e condensa múltiplos discursos contemporâneos, que pode aludir às diversas juventudes e aos diferentes modos de ser jovem. Multiplicidade discursiva que se condensa em algo que é proliferado por uma grande teia de pequenos nódulos. Para Bachelard (1993: 184) "há formas complexas que mesmo em repouso fazem barulho". É preciso escutar a juventude mesmo sabendo que eles não têm todas as respostas, quiçá, resposta alguma. Porém, seus gritos são de múltiplas e complexas problematizações sobre si, sobre o outro, sobre o grupo, sobre o espaço de convivência e sobre a cidade que os envolve.

\section{À guisa de conclusão}

Toda cidade é sempre encoberta por uma névoa que não há a deixa ser vista. Estar distante impede de compreender a essência que brota da sua vivacidade, da sua vivência que pulsa. Aproximar-se dela dá a possibilidade de senti-la palpitando, pois os emaranhados que a constitui dificulta enxergá-la na sua completude. Se preferir, podese passar por ela, sem perceber o que se passa, pois o cotidiano é esse constante passar, quando nada passa (Pais, 1993). A cidade afeta as pessoas, diariamente, e é afetada por elas, na mesma proporção, sem que ambas se notem. E nessa constância, cidade e pessoas são guinadas e sofrem as transformações. Olhares, sorrisos, afetos, prioridades, 
tudo muda. Nova cidade, novas pessoas, outras relações, todas as transformações ainda no mesmo corpo. Em algumas vezes, elas se descobrem, mas em outras, porém, o cotidiano segue o seu curso normal. Ora oprimindo suas margens, ora sendo oprimido por elas. Isso, até as águas subirem novamente.

Por esse prisma, procurou-se, aqui, trazer uma abordagem que priorizasse o urbano na sua complexidade e nas miudezas cotidianas. $\mathrm{O}$ grupo de skatista observado, mesmo fixado num mesmo lugar, possibilitou olhar a cidade de uma maneira sútil, para elucidar uma urbe que os entrelaçamentos criados pela polis não dão conta de desatar. A cidade é potência de encontro, com vida própria e com movimentos carregados de dinamicidade. Os skatistas, com suas impermanências e movimentações, possibilitaram enxergar a intensidade nas suas percepções e nas suas relações com a cidade. Cada um, com seu jeito próprio, apodera-se dos lugares, ancorados pelos interesses do grupo, pois a apropriação dos espaços se dá de forma momentânea e acontecem, em sua maioria, juntamente com o grupo. Com isso, cada novo espaço percebido na cidade, pode se tornar um pico diferente, pois seus olhos são perscrutadores de locais skatáveis. Essa atitude acaba sendo limitadora de uma experiência mais completa da cidade, pois as ações $\mathrm{s}$ voltam apenas ao skate, o que impossibilita um alargamento das experimentações, que não se esbarrem nos limites impostos pela preferência skatista.

Nas suas andanças, os skatistas demostram uma avidez na busca por boas imagens. Seja em fotografias ou em vídeos, a captura de imagem é sempre constante. A maioria prefere o vídeo, por este dar conta de apresentar o movimento da manobra com mais exatidão e, ainda, pela necessidade de mostrar aquelas perspicácias realizadas com perfeição. Se forem perfeitas, devem ser apresentadas aos pares que não acompanharam a manobra ao vivo, pois a aprovação e os elogios são importantes, sobretudo se houve dificuldade em executá-la. A internet torna-se aliada fiel para resolver o problema daqueles que não estavam presentes. O youtube, o facebook, o instagram é o espaço virtual para ajudar a galera. A fotografia ou o vídeo trazem um pouco da manobra realizada, a proeza do skatista que a realizou, do lugar em que tudo aconteceu e, ainda, da cidade que acolhe e possibilita todos esses nódulos. As imagens contribuem na construção do imaginário da cidade. Outros formatos comunicacionais como o cinema e a literatura, a pintura também dão suas contribuições. Na maioria das vezes, esses suportes são as únicas referências de um passado remoto, ou mesmo recente, da cidade 
aborda. Uma imagem que se constrói encharcada das intencionalidades, dos objetivos e das ideologias das pessoas que estão diretamente ligadas ao ato fotográfico. Quando veiculadas na internet, as imagens permanecem à disposição dos pares, dos simpatizantes, do público em potencial e de outros que podem acessar esporadicamente.

As imagens, como expressão de uma experiência vivenciada, trazem os vestígios de um conteúdo partilhado, que resulta da impressão de quem as produziu. Mesmo carregadas de intencionalidades, elas trarão impregnadas os ecos visuais dos ambientes que compuseram a cena. Cada lugar registrado é convidado a ser uma referência, por vezes única, daquele cenário e intimado a reconstituir-se, sempre que visibilizado, como uma testemunha verdadeira. A cidade se vale dessa prerrogativa para perpetuar-se no imaginário coletivo. Ao emprestar-se para ser fotografada, ela se agarra a imagem para nunca mais largar. Assim, ela garante uma existência visual perene. Os skatistas, com suas andanças e seus discursos imagéticos, contribuem para a permanência perpétua dos lugares visitados no imaginário das pessoas. Esses são caminhos que o percurso do trabalho sugeriu seguir. Espera-se que as problematizações apontadas reverberem para suscitar outros trajetos, mais densos ou, mesmo, menos pantanosos.

\section{REFERÊNCIAS}

BACHELARD, Gaston. A poética do espaço. DANESI, Antonio P. (Trad.) e ABILIO,

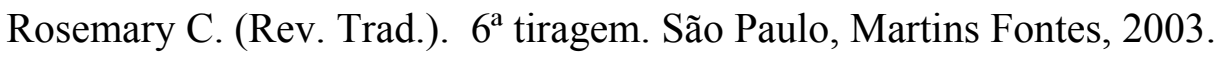

BARTHES, Roland. A Câmara Clara. São Paulo, Nova Fronteira, 1984.

BASTOS, Billy Graeff. Estilo de vida e trajetórias sociais de skatistas: da "vizinhança" ao "corre". Dissertação de Mestrado em Ciências do Desenvolvimento Humano Programa de Pós-Graduação em Ciências do Desenvolvimento Humano, Escola de Educação Física. Porto Alegre-RS, UFRGS, 2006.

BRUNO, Fernanda. Máquinas de ver, modos de ser: vigilância, tecnologia e subjetividade. Porto Alegre-RS, Sulina, 2013.

CALVINO, Ítalo. As cidades invisíveis. MAINARDI, Diogo (Trad.). São Paulo-SP, Companhia das Letras, 1993. 
CARVALHO, Walter; JARDIM, João. JANELA DA ALMA. documentário, Copacabana Filmes, Brasil, 2001, 73 minutos.

DELEUZE, Gilles; GUATTARI, Fêlix. "587 a.C. - 70 d.C. - Sobre alguns regimes de signos". In. . Mil Platôs - capitalismo e esquizofrenia, vol. 2. OLIVEIRA, Ana M.; LEÃO, Lúcia C. (Trad.). Rio de Janeiro, 34, 1995.

ESCALLIER, Christine. "La construction du regard em anthropologie de l'éducation: une ethno-pédagogie de l'image". In. Arquivos da memoria (Antropologia, arte e imagem), Portugal, nºs. 5-6, (Nova Série), 2009, p. 152-165.

LIMA, Ivan. A fotografia é a sua linguagem. FIRMO, Walter (Apres.). Rio de Janeiro, Espaço Tempo, 1988.

MACHADO, Giancarlo M. C. De "carrinho" pela cidade: a prática do street skate em São Paulo. Dissertação de Mestrado, Programa de pós-graduação em antropologia social, Departamento de Antropologia. São Paulo, FFLCH-USP, 2011.

MACHADO, Arlindo. A Ilusão Especular. Introdução à Fotografia. Rio de Janeiro, Brasiliense, Funarte, 1984.

MAFFESOLI, Michel. O tempo das tribos: o declínio do individualismo na sociedade de massa. NEVES, Luiz F. B. (Apres.); MENEZES, Maria d. L. (Trad.); VOGEL, Arno (Rev. Tec.). $2^{\mathrm{a}}$ ed. Rio de Janeiro-RJ, Forense Universitária, 1998.

MÁRQUEZ, Israel; GARCÍA, Rubén Díez. "La cultura skate en las sociedades contemporáneas: una aproximación etnográfica a la ciudad de Madrid”. In. EMPIRIA. Revista de Metodología de Ciencias Sociales. N.o 30, enero-abril, 2015, pp. 133-158.

MARTÍN-BARBERO, Jesús. "Cidade virtual: novos cenários da comunicação”. In. Comunicação \& Educação, São Paulo, (11), 53 a 67, jan./abr. 1998.

OLIVEIRA, Flávio G.; CARDOSO, Iuri A.; BERALDO, Rosa M. "A câmera animada". MONTEIRO, R. H. e ROCHA, C. (Orgs.). In. Anais do VI Seminário Nacional de Pesquisa em Arte e Cultura Visual. Goiânia-Go, UFG, FaV, 2013.

PAIS, José Machado. "Nas rotas do quotidiano". In. Revista Crítica de Ciências Sociais, no 37, s. L., junho-1993, p. 105-115. 
PAREDES, Tatiana Millán. "La digitalización de la realidade en las nuevas generaciones del siglo XXI". In. Comunicar - Revista Científica de Comunicación y Educación. Badajoz-ES, 26, 2006. p. 171-175.

PARENTE, André. "Cinema em trânsito: do dispositivo do cinema ao cinema do dispositivo". In: PENAFRIA, Manuela; MARTINS, Índia Mara (Org.). Estéticas do digital: Cinema e Tecnologia. Covilhã-PT, Livros LabCom, 2007.

REGUILLO CRUZ, Rossana. Emergencia de culturas juveniles: estrategias del desencanto. Buenos Aires, Norma, 2000.

ROA, Alberto Saldarriaga. "Imagen y memoria en la construcción cultural de la ciudad". In. TOVAR, Carlos A. T.; MONSALVE, Fernando V.; HERNÁNDEZ, Edmundo P. (Comp.). La ciudad: Hábitat de diversidad y complejidad. 2a ed. Bogotá, Unibiblo, 2002.

SÁNCHEZ MONTALBÁN, Francisco J. "La ciudad poseída. Miradas fotográficas sobre lo urbano como fuente de conocimiento social". In. Zainak. 23, 2003, p. 71-88.

SARAVÍ, Jorge Ricardo. Skate, espacios urbanos y jóvenes en la ciudad de La Plata. Maestría em Educación Corporal, Facultad de Humanidades y Ciencias de la Educación. La Plata, Universidad Nacional de La Plata, 2012.

SOLÀ-MORALES, Ignasi. “Terrain Vague”. In. Anyplace, Cambridge, MA, Mit Press, 1995, p. 118-123.

TOMAZ, Ana Kalassa El Banae. "Uma cidade entre imagens". In. Proj. História, São Paulo, (24), junho, 2002, p. 431-449.

TUSET, Juan J. "La recuperación de lo Otro: enfoque a las imágenes de arquitectura". In. DC 24, vol.11, Valencia, 2012, p. 91-100.

Recebido: $31 / 05 / 2020$

Aprovado: 04/09/2020 